\title{
Cost-effectiveness of ticagrelor versus clopidogrel in patients with acute coronary syndromes in Canada
}

This article was published in the following Dove Press journal:

ClinicoEconomics and Outcomes Research

24 January 2014

Number of times this article has been viewed

\author{
Daniel T Grima' \\ Stephen T Brown' \\ Laveena Kamboj ${ }^{2}$ \\ Kevin R Bainey ${ }^{3}$ \\ Ron Goeree ${ }^{4,5}$ \\ Paul $\mathrm{Oh}^{6}$ \\ Krishnan Ramanathan ${ }^{7}$ \\ Shaun G Goodman ${ }^{8}$ \\ 'Cornerstone Research Group, \\ Burlington, ON, ${ }^{2}$ AstraZeneca Canada, \\ Mississauga, ON, ${ }^{3}$ Mazankowski \\ Alberta Heart Institute/University \\ of Alberta Hospital, Edmonton, \\ $\mathrm{AB},{ }^{4}$ Program for Assessment of \\ Technology in Health, St Joseph's \\ Hospital, Hamilton, ON, ${ }^{5}$ Department \\ of Clinical Epidemiology and \\ Biostatistics, McMaster University, \\ Hamilton, ON, 'University Health \\ Network, Toronto, ON, ${ }^{7}$ St Paul's \\ Hospital, Vancouver, BC, ${ }^{8}$ St Michael's \\ Hospital, University of Toronto, \\ Toronto, ON, Canada
}

Correspondence: Daniel T Grima Cornerstone Research Group Inc, 204-3228 South Service Road, Burlington, Ontario, Canada, L7N 3H8 $\mathrm{Tel}+\mid 905637623$ I

Fax +I 9056375014

Email dgrima@cornerstone-research.com
Background: Ticagrelor demonstrated a significant reduction in major cardiac events in patients with acute coronary syndrome (ACS) compared with clopidogrel in the Platelet Inhibition and Patient Outcomes (PLATO) trial. The objective of this study was to assess the cost-effectiveness of ticagrelor compared with clopidogrel in ACS patients from the perspective of the Canadian publicly funded health care system.

Methods: A two-part model was developed consisting of a 1-year decision tree and a lifetime Markov model. Within the decision tree, patients remained event-free, experienced a nonfatal myocardial infarction, a nonfatal stroke, or death due to vascular or nonvascular related causes based on data from the PLATO trial. The lifetime Markov model followed these patients and allowed for subsequent myocardial infarction, stroke, and death. Patient utility and resource use were derived from the PLATO trial. Transition probabilities and specific Canadian unit costs were derived from published sources. Univariate and probabilistic sensitivity analyses were conducted.

Results: In the base case lifetime analysis, treatment with ticagrelor resulted in more years of life per person (0.097), more quality-adjusted life years per person (QALYs, 0.084), and an incremental cost per QALY gained of \$9,745 (Canadian\$), assuming a generic cost for clopidogrel. A probabilistic sensitivity analysis demonstrated the robustness of the base case analysis, with a 93\% probability of being below $\$ 20,000$ per QALY gained and a 99\% probability of being below \$30,000 per QALY gained.

Conclusion: Ticagrelor is a clinically superior and cost-effective option for the prevention of thrombotic events among ACS patients in Canada.

Keywords: acute coronary syndrome, percutaneous coronary intervention, cost-effectiveness analysis, cost-utility analysis, clopidogrel, ticagrelor, antiplatelet therapy

\section{Introduction}

Acute coronary syndromes (ACS) are most commonly caused by plaque disruption with exposure of substances that promote platelet activation, adhesion and aggregation, thrombin generation, and thrombus formation leading to partial or complete occlusion of one or more coronary arteries. In Canada, ACS has been estimated to result in 22,000 deaths and 109,000 hospitalizations, of which 77\% were due to myocardial infarction (MI) and 23\% to unstable angina. ${ }^{1}$

In patients who have ACS with or without ST-segment elevation, clinical practice guidelines at the time of the ticagrelor trials recommended dual antiplatelet treatment with acetylsalicylic acid and clopidogrel. ${ }^{2}$ However, the antiplatelet effect of this combination of oral therapies is variable due to interpatient extrinsic or intrinsic 
mechanisms and contributes in part to the recurrence of serious cardiovascular events in approximately $10 \%$ of clopidogrel-treated ACS patients. ${ }^{3-5}$ Updated guidelines now recommend ticagrelor, a direct-acting oral P2Y12-receptor antagonist that binds reversibly to its receptor, as a better alternative to clopidogrel. ${ }^{6}$ Ticagrelor provides greater and more consistent platelet inhibition than clopidogrel, with a more rapid onset and offset of action. ${ }^{7}$ Ticagrelor use is supported by the PLATO (PLATelet inhibition and patient Outcomes) trial, an international study of ACS patients $(n=18,624)$ that included 30 Canadian centers. The PLATO trial demonstrated that ticagrelor was superior to clopidogrel for the primary composite efficacy endpoint (a composite of cardiovascular mortality, MI, or stroke; hazards ratio [HR] 0.84; 95\% confidence interval [CI] 0.77-0.92, $P<0.001$ ). Predefined hierarchical testing of secondary endpoints found significant differences in recurrent MI (HR 0.84; 95\% CI 0.75-0.95, $P=0.005$ ) and cardiovascular death (HR $0.79 ; 95 \%$ CI $0.69-0.91, P<0.001) .{ }^{8}$ The PLATO trial also showed that there was no significant increase in the rate of overall PLATO-defined major bleeding (HR 1.04; 95\% CI 0.95-1.13).

The extent to which ticagrelor will be used in Canada depends not only on its relative efficacy but also on its economic value. Cost-effectiveness analyses of ticagrelor versus clopidogrel based on the PLATO trial have found favorable lifetime incremental cost per quality-adjusted life year (QALY) ratios (range US\$2728-US\$8443) from public payer perspectives in Germany, Singapore, Australia, and the UK, ${ }^{9-13}$ and have resulted in coverage by public plans in several countries. A "do not list" recommendation for ticagrelor was made by the Canadian Common Drug Review based in part on the perceived limitations of previously developed cost-effectiveness models. ${ }^{14}$ The analysis reported herein assesses the long-term cost-effectiveness of ticagrelor versus clopidogrel in ACS patients from the perspective of the Canadian publically funded health care system and reflects modifications to the originally submitted models. Notably, the current model allows the occurrence of multiple clinical events (eg, stroke and MI) over a lifetime, with the occurrence of future events influenced by previous clinical events. This revised model was used in provincial reimbursement discussions, which have resulted in funding for ticagrelor. ${ }^{15}$

\section{Materials and methods}

The economic analysis was based on a two-part costeffectiveness model, comprised of a decision tree covering the first year following occurrence of ACS, combined with a Markov model to capture costs and outcomes over the remainder of the patients' lifetime. Efficacy and safety data from the PLATO trial were used to inform treatment effectiveness over the first year of the model. The main clinical outcomes of interest were vascular or nonvascular death, nonfatal MI, and stroke. Costs and outcomes were discounted at a rate of $5 \%$ per year as per Canadian guidelines. ${ }^{16}$ The base case analysis used a lifetime time horizon to capture the short-term and long-term impacts of antiplatelet therapy on death and nonfatal cardiovascular events.

\section{Patient population and treatment}

The model was populated with data from the PLATO trial, which included a broad spectrum of ACS patients (ie, STsegment elevation MI, non-ST-elevation MI, and unstable angina) who were hospitalized within 24 hours of symptom onset. Patients in the trial could undergo invasive management (ie, coronary angiography and percutaneous coronary intervention or coronary artery bypass grafting, where appropriate) or be managed medically (with or without angiography). Baseline patient characteristics included a median age of 62 years, predominantly male sex $(72 \%)$, and cardiovascular risk factors such as hypertension $(65 \%)$ and dyslipidemia (47\%). Patients in the PLATO trial were randomized to receive a maximum of 1 year of therapy with ticagrelor or clopidogrel, both given in addition to aspirin. ${ }^{8}$ Ticagrelor was given in a loading dose of $180 \mathrm{mg}$ followed by a $90 \mathrm{mg}$ dose twice a day. Clopidogrel was given in a loading dose of 300 or $600 \mathrm{mg}$ followed by a $75 \mathrm{mg}$ dose daily.

\section{I-year decision tree}

The 1-year decision tree was modeled based on clinical events (first and subsequent), resource utilization, and utility data collected in the PLATO trial. The model included patient pathways for new non-fatal MI, new non-fatal stroke, or death from vascular or nonvascular causes. Patients not experiencing these events were considered event-free over the 1-year treatment period (Figure 1). ${ }^{8}$ The probabilities of a patient in the PLATO trial having a nonfatal MI, nonfatal stroke, or dying from any cause were calculated from published PLATO trial data (Table 1). ${ }^{12}$ The majority $(89.4 \%$ ) of patients in the PLATO trial did not experience an event after the initial occurrence of ACS. A further $9.1 \%$ of patients experienced only one clinical event (MI, stroke, or death) and approximately $1.5 \%$ of the PLATO trial patients had multiple events (MI, stroke, or death). As such, the four health states of the decision tree captured the majority of patient pathways from 


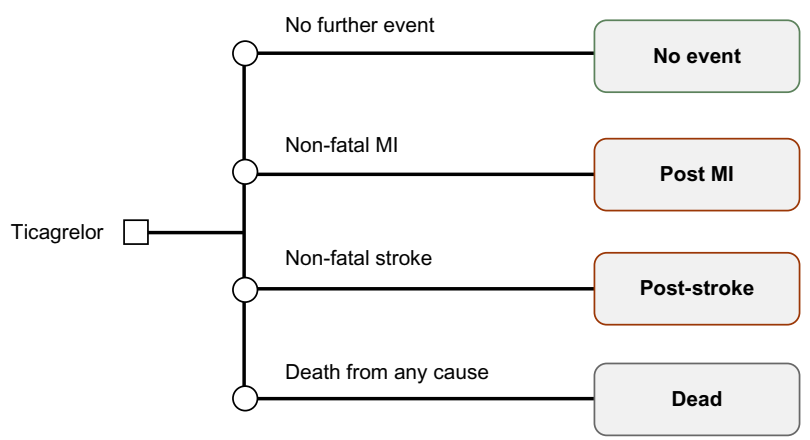

Decision tree replicated for clopidogrel arm

Figure I Model diagram of the I-year decision tree. Abbreviation: MI, myocardial infarction.

the PLATO trial. Those patients who had an event and died within the first year were included in the dead group for calculating probabilities of events; the remainder were grouped based on the first event experienced. Transition probabilities for ticagrelor patients were calculated by applying the HRs from the PLATO trial to the probabilities for clopidogrel patients, after converting such probabilities to rates. ${ }^{17}$

\section{Lifetime Markov model}

At the end of the 1-year decision tree, a Markov state transition model (Figure 2) was used to simulate the natural history of ACS patients from the PLATO trial over their remaining lifetime. Similar to the model structure used in the Canadian Agency for Drugs and Technologies in Health Technology Report on antiplatelet therapy use in ACS, ${ }^{18}$ the Markov model states included post-MI/no event, post-stroke, new MI, new stroke, vascular death, or nonvascular death. In this model, patients can have multiple events over time. Specifically, patients entered the Markov model based on the events in the 1-year decision tree. Patients who did not have an event in the 1-year decision tree model entered the post-MI state, as $80 \%$ of the PLATO study participants had an MI as their index ACS event. Patients who experienced an MI or stroke in the 1-year decision tree entered the new MI and new stroke

Table I One-year decision tree event probabilities

\begin{tabular}{llllll}
\hline Clinical Pathway & \multicolumn{2}{c}{ Clopidogrel $\mathbf{n = 9 , 2 9 I}$} & & \multicolumn{2}{c}{ Ticagrelor $\mathbf{n = 9 , 3 3 3}$} \\
\cline { 2 - 3 } \cline { 5 - 6 } & $\mathbf{N}$ & Proportion & & $\mathbf{N}$ & Proportion \\
\hline I. No Events & 8,226 & 0.8854 & & 8,432 & 0.9035 \\
2. MI & 485 & 0.0522 & & 421 & $0.045 I$ \\
3. Stroke & 74 & 0.0080 & & 81 & 0.0087 \\
4. Dead any cause & 506 & 0.0545 & & 399 & 0.0428 \\
\hline
\end{tabular}

Note: Copyright (C) 2013. Oxford University Press. Reproduced from Nikolic E, Janzon M, Hauch O, Wallentin L, Henriksson M. Cost-effectiveness of treating acute coronary syndrome patients with ticagrelor for 12 months: results from the PLATO study. Eur Heart J. 20 I3;34(3):220-228 by permission of Oxford University Press. ${ }^{12}$ Abbreviation: MI, myocardial infarction. states, respectively, in the Markov model. After 1 year in the new MI and new stroke states, patients transitioned to the corresponding post-event state. In each 1-year cycle, patients could experience a new MI, new stroke, vascular death, or nonvascular death, or remain in a post-event state. Patients could not enter the new MI state from the post-stroke state because this would allow stroke patients to transition to a health state characterized by an improved quality of life and lower associated costs. ${ }^{18}$ Probabilities for MI, stroke, and vascular death that reflected the history of previous events were based on published logistic and multinomial regression equations (see Supplementary material for values). ${ }^{18,19}$ The probabilities of nonvascular death were based on sex-specific Canadian life tables for noncardiovascular-related death. ${ }^{20}$ These probabilities were weighted based on the proportion of males to females reported in the PLATO trial.

\section{Health-related utility values}

The utility values used for each of the model health states in the 1-year decision tree were obtained from EuroQol-5D data collected in the PLATO trial and represent the accrued utility over a 12 -month period (Table 2 ). ${ }^{8}$ Given that the utility values were not statistically significant between the two treatment groups in the PLATO trial, the mean utility values for all patients in each event state were used. The utility values from the PLATO trial for MI and stroke were also used in the lifetime Markov model. The utility value for post-stroke was assumed to be the same as for new stroke. The utility associated with the post MI/no event state was based on the utility for MI from the trial plus the improvement in utility observed over 1 year after MI as reported by Lacey and Walters. ${ }^{21}$ Based on PLATO trial data, patients who died were assigned the accrued utility up to the point at which they entered the dead health state.

Rates of dyspnea were higher in the ticagrelor group than in the clopidogrel group ( $13.8 \%$ versus $7.8 \%$, respectively). However, most reported symptoms of dyspnea were mild to moderate in intensity and presented as a single episode following soon after initiation of treatment. Approximately $30 \%$ of episodes resolved within 7 days, and the rate of discontinuation due to dyspnea was $0.9 \%$ with ticagrelor versus $0.1 \%$ with clopidogrel. ${ }^{22}$ As such, the health utility impact of this event was assumed to be minimal and was excluded from the base case analysis but examined in a sensitivity analysis. Similarly, the impact of major bleeding events was not considered in the analysis because no difference in rates of major bleeds was observed in the PLATO trial (11.6\% for ticagrelor versus $11.2 \%$ for clopidogrel, $P=0.43){ }^{8}$ 


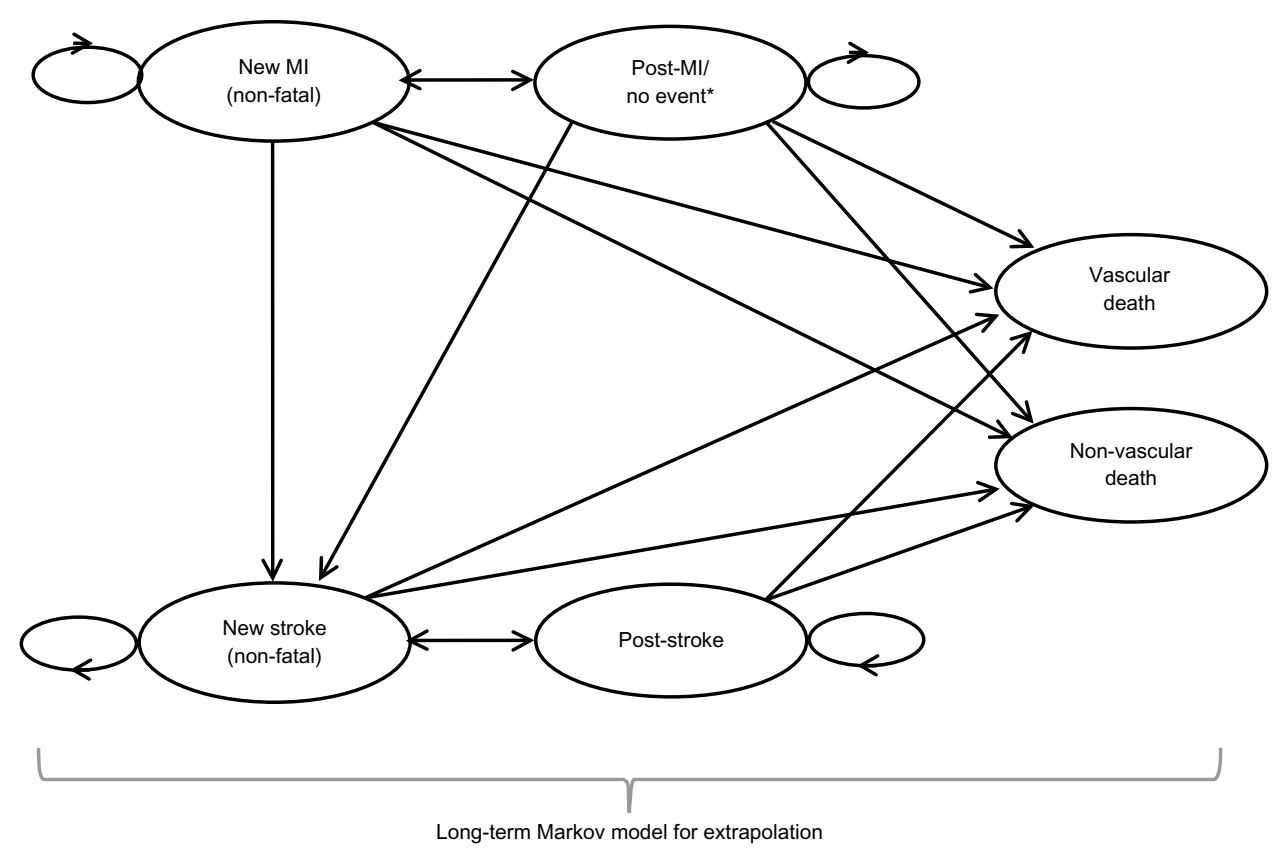

Figure 2 Diagram of the Markov model for post-I-year.

Note: *This state includes patients who had no events within the year after the incident hospitalization for ACS and patients who had an MI in the first year after the ACS event. Abbreviations: $\mathrm{MI}$, myocardial infarction; ACS, acute coronary syndrome.

\section{Resources and costs}

The mean 12-month resource use for PLATO trial patients was used to calculate health state costs in the first year of the analysis. ${ }^{12}$ The PLATO trial provided data on the average days of hospitalization and the number and type of interventions and procedures that occurred in each arm of the trial. Hospital days reflected the initial (index) hospitalization for ACS and hospitalizations for other events (eg, MI, stroke) and procedures (eg, coronary artery bypass grafting). To avoid double counting of the hospital stay, a unit cost was applied to days of hospitalization while only the additional costs beyond hospital stay were applied for each procedure/ intervention. Specifically, unit costs from the Ontario Case

Table 2 Health-related utility values used in the model

\begin{tabular}{lll}
\hline State & $\begin{array}{l}\text { I-year decision } \\
\text { tree* }\end{array}$ & $\begin{array}{l}\text { Markov } \\
\text { model** }\end{array}$ \\
\hline No further event & 0.875 & 0.854 \\
New MI (nonfatal) & 0.812 & 0.812 \\
New stroke (nonfatal) & 0.736 & 0.736 \\
Post-MI & - & 0.854 \\
Post-stroke & - & 0.736 \\
All-cause death & 0.249 & 0.0 \\
\hline
\end{tabular}

Notes: *Utilities for I-year decision represent the average utility values reported in the PLATO trial for ticagrelor and clopidogrel. The utility value for "dead any cause" represents the utility value accrued by the patient before they died. **Data from Banerjee et al. ${ }^{18}$ No further event state utilities were assumed to be the same as the post-Ml state utilities. New stroke and post-stroke utility values were assumed to be the same as there is no evidence health-related quality of life improves over time.

Abbreviations: Ml, myocardial infarction; PLATO, Platelet Inhibition and Patient Outcomes.
Costing Initiative and from the Ontario Ministry of Health and Long-Term Care were used to value health care resources consumed during the PLATO trial. ${ }^{23,24}$ The 1-year health state costs, calculated from the PLATO trial, were lower in the ticagrelor treatment arm compared with the clopidogrel treatment arm (Table S1). A detailed description of Canadian unit costs is presented in Table S2. In order to be conservative, the 1-year treatment costs were averaged such that no difference in health state costs was modeled between treatments. ${ }^{12}$ Costs for the Markov model were obtained from published Canadian estimates. ${ }^{18}$ All costs were inflated to reflect 2011 Canadian dollars (Table 3). The exchange rate at the time of preparation was Canadian (CDN)\$1 equal to US\$0.97.

Total costs of $\$ 2.96$ and $\$ 0.645$ for ticagrelor $(90 \mathrm{mg}$ twice daily) and generic clopidogrel ( $75 \mathrm{mg}$ once daily), respectively, were assumed in the base case analysis. Generic clopidogrel

Table 3 Resource costs used in the I-year decision tree and post-I-year Markov model

\begin{tabular}{lll}
\hline State & $\begin{array}{l}\text { I-year decision } \\
\text { tree }\end{array}$ & $\begin{array}{l}\text { Markov } \\
\text { model* }\end{array}$ \\
\hline No further event & $\$ 2 I, 78 I$ & $\$ 3,15 \mathrm{I}$ \\
New MI (nonfatal) & $\$ 45,515$ & $\$ 10,96 \mathrm{I}$ \\
New stroke (nonfatal) & $\$ 55,445$ & $\$ 21,087$ \\
Post-MI & - & $\$ 3,15 \mathrm{I}$ \\
Post-stroke & - & $\$ 4,39 \mathrm{I}$ \\
All-cause death & $\$ 39,630$ & $\mathrm{~N} / \mathrm{A}$ \\
\hline
\end{tabular}

Notes: Values inflated to $201 \mathrm{I}$ (Canadian dollars) and rounded for display. *Data from Banerjee et al. ${ }^{18}$ No further event state costs were assumed to be the same as the post-MI state costs.

Abbreviations: $\mathrm{Ml}$, myocardial infarction; N/A, not applicable. 
costs were estimated assuming pricing at $25 \%$ of brand name clopidogrel at $\$ 2.58$. Costs for a $180 \mathrm{mg}$ ticagrelor and $300 \mathrm{mg}$ clopidogrel loading dose were also included. Costs for acetylsalicylic acid were excluded because acetylsalicylic acid is not uniformly listed on all Canadian provincial formularies and the use between treatment arms was similar. The rates of dyspnea were significantly different between ticagrelor and clopidogrel (13.8\% versus $7.8 \%$, respectively); however, such events were mild or moderate in intensity. ${ }^{8}$ While the utility impact of these events was not explicitly modeled, it was assumed that these patients would require an extra two physician visits for assessment and monitoring purposes (\$70.80). ${ }^{24}$ This is similar, although more conservative, than an assumption in a recent economic analysis of ticagrelor that assumed dyspnea had no treatment costs. ${ }^{25}$

\section{Other model assumptions}

The following assumptions were made for the base case analysis: no treatment effect after year 1 of the model was assumed, because all transition probabilities were the same for both treatment arms; adverse events such as dyspnea had no long-term prognostic impact beyond the duration of the clinical trial; no discontinuation other than due to death was included in the model; and the length of treatment for both ticagrelor and clopidogrel was assumed to be 365 days for those who survived the 1-year trial period. For those patients who died during the year, the length of treatment was assumed to be 183 days, assuming that they died, on average, mid-way through the year.

\section{Subgroup and sensitivity analyses}

Analyses were conducted for key subgroups identified in the PLATO trial. ${ }^{8}$ Sensitivity analyses were conducted to test the robustness of the cost-effectiveness model and the impact of the input variables on the results. One-way sensitivity analyses were conducted on key parameters such as baseline event rates, costs, QALY values, and age-specific event rates (Table S3). For the majority of the inputs, the $95 \%$ CIs were used to inform low and high values. However, in instances where 95\% CIs were not available, the input was varied by $\pm 20 \%$. Probabilistic sensitivity analyses were also undertaken (see Table S4 for inputs and distributions). Event rates, HRs, utility values, and resource costs were varied simultaneously using Monte Carlo simulation. Multi-way sensitivity analyses using alternative data sources for costs and utility data were also conducted: a) increased and b) decreased unit costs by $20 \%$ to explore the impact of uncertainty and variability in resource costs; c) used costs and utilities for events derived from a Canadian Agency for Drugs and Technologies in Health analysis of antiplatelet agents in the treatment of ACS, ${ }^{18}$ because this was considered the most relevant alternative data source for Canadian analysis; discounted rate for costs and outcomes changed to d) $0 \%$ and e) $3 \%$; f) changed utility values for post-MI and no event in the Markov model from 0.854 to 0.875 based on alternative utility estimate from the PLATO study; g) the PLATO trial found nonsignificant differences in resource use and health utility between the ticagrelor and clopidogrel arms of the study (these values were used in a sensitivity analysis instead of the pooled values); h) transition probabilities based on a Weibull regression from a published analysis were used; ${ }^{12}$ i) treatment-specific data for days of study drug were used (ticagrelor and clopidogrel values were 292 and 299 days for no event patients, 269 and 287 days for MI patients, 189 and 212 days for stroke patients, and 66 and 77 days for dead by any cause patients, respectively).

\section{Results}

\section{Base case analysis}

The base case analysis demonstrated that ticagrelor is costeffective compared with generic clopidogrel, with an incremental cost per life year gained of $\$ 8,438$ and an incremental cost per QALY of $\$ 9,745$ over a period of 40 years $(0.084$ QALY gained) due to lifetime gains of 0.097 life years per patient, 0.084 QALYs per patient, and an incremental lifetime cost of $\$ 821$ per patient. Incremental cost-effectiveness ratios (ICERs) increased with decreasing time horizon, with results remaining under $\$ 16,000$ per QALY gained even for time horizons as low as 5 years (Table 4 ).

\section{Subgroup and sensitivity analyses}

The mean results from the probabilistic sensitivity analysis (5,000 simulations) indicated that the deterministic results are robust (Table 5, Figures 3 and 4). The univariate analyses indicated that the greatest sensitivity of ICERs was to variability around the HR of death for ticagrelor versus clopidogrel (Figure 5). The cost-effectiveness acceptability curves showed a $93 \%$ probability of ticagrelor being cost-effective at a willingness-to-pay of $\$ 20,000$ per QALY and 99\% probability of being cost-effective at a willingness-to-pay of $\$ 30,000$ per QALY (Figure 4). Univariate and multi-way sensitivity analyses indicated that the ICERs were also robust to plausible changes in the input parameters (Figure 5, Tables S5 and S6). Values for the multi-way sensitivity analyses were a) $\$ 8,902$, b) $\$ 10,586$, c) $\$ 14,874$, d) $\$ 8,258$, e) $\$ 9,138$, f) $\$ 9,555$, g) $\$ 4,743$, h) $\$ 9,907$, and i) $\$ 7,587$. Changes to the HR for death with ticagrelor compared with clopidogrel resulted 
Table 4 Summary of discounted cost-effectiveness results for different time horizons

\begin{tabular}{cllll}
\hline $\begin{array}{l}\text { Time } \\
\text { horizon }\end{array}$ & Ticagrelor & Clopidogrel & Incremental & ICER \\
\hline 40 years & & & & \\
Costs & $\$ 52,490$ & $\$ 51,669$ & $\$ 821$ & \\
Life-years & 8.308 & 8.211 & 0.097 & $\$ 8,438$ \\
QALYs & 7.016 & 6.932 & 0.084 & $\$ 9,745$ \\
20 years & & & & \\
Costs & $\$ 51,393$ & $\$ 50,586$ & $\$ 807$ & \\
Life-years & 8.041 & 7.947 & 0.094 & $\$ 8,598$ \\
QALYs & 6.801 & 6.720 & 0.081 & $\$ 9,900$ \\
I0 years & & & & \\
Costs & $\$ 44,801$ & $\$ 44,079$ & $\$ 722$ & \\
Life-years & 6.342 & 6.269 & 0.072 & $\$ 9,983$ \\
QALYs & 5.386 & 5.322 & 0.064 & $\$ 11,329$ \\
5 years & & & & \\
Costs & $\$ 36,195$ & $\$ 35,582$ & $\$ 613$ & \\
Life-years & 4.040 & 3.996 & 0.044 & $\$ 14,046$ \\
QALYs & 3.442 & 3.402 & 0.040 & $\$ 15,441$ \\
\hline
\end{tabular}

Note: All values are in Canadian dollars.

Abbreviations: ICER, incremental cost-effectiveness ratio; QALYs, quality-adjusted life years.

in the largest impact $(\$ 17,685$ per QALY); other analyses produced ICERs below $\$ 12,000$ per QALY. The ICERs were consistent across all key subgroups (Table S6).

\section{Discussion}

The PLATO trial demonstrated a significant reduction in a composite of major cardiac events (cardiovascular death, MI, and stroke) and mortality among ACS patients who were treated for up to 1 year with ticagrelor compared with clopidogrel. ${ }^{8}$ The results of the cost-effectiveness analysis and the sensitivity analyses show that for patients with ACS, 12 months of antiplatelet therapy with ticagrelor is highly cost-effective compared with generic clopidogrel in the Canadian health care system, with an incremental cost per QALY gained of $\$ 9,745$ in the base case scenario. These results strongly support the adoption of ticagrelor for the treatment of ACS patients in Canada, based both on clinical and economic value ${ }^{26}$ and have lower ICERs than reported for clopidogrel. ${ }^{18}$

A strength of this analysis includes use of clinical data derived from a large randomized, controlled, head-to-head trial used to compare ticagrelor with the current standard of care, clopidogrel, which has already been established as a cost-effective treatment for ACS..$^{18}$ In addition, the PLATO trial included the use of clinically relevant outcomes, such as MI, stroke, and death, as the trial endpoints. In this way, use of data from the PLATO trial avoided the two most common limitations in economic analyses, ie, use of comparators that do not reflect current practice and use of intermediate endpoints that require extrapolation to clinically relevant outcomes.

Within any modeling study, it is critical to test the robustness of the results based on uncertainty in the input parameters. In this regard, extensive sensitivity analyses were conducted using the CIs from the PLATO trial and alternative data inputs based on Canadian data sources wherever possible. The results of the probabilistic analysis, which varied the event rates, costs, and utilities, support the deterministic base case results with a ratio of $\$ 9,942$ (95\% CI $\$ 9,764-\$ 10,120)$ per QALY, with $93 \%$ probability of a ratio below \$20,000 per QALY gained. These results fall well below commonly quoted acceptable ICER thresholds, so present a strong economic support for adoption. The oneway sensitivity analyses indicated that the results were most sensitive to the $\mathrm{CI}$ around the HR for death for ticagrelor relative to clopidogrel; however, in the worst case, the ICER remained strong at $\$ 17,685$ per QALY.

As in all models, limitations occur due to application of trial findings to real-world clinical practice, data assumptions, and structural choices. The analysis results are primarily driven by the mortality differences observed in the PLATO trial between ticagrelor and clopidogrel. However, to capture the impact of differences in mortality between therapies in the year of treatment, the model had to extrapolate beyond the 12-month follow-up period of the PLATO trial. In this way, the value of deaths prevented in year 1, ie, added years of life, could be captured. Such an approach is common in health economic studies ${ }^{18}$ and reflects Canadian health economic guideline recommendations. ${ }^{16,17}$ It is noteworthy that most of the benefit is achieved in the first few years of the extrapolation, with the cost per QALY gained for ticagrelor compared with clopidogrel remaining low $(\$ 15,441)$ even with only a 5-year time horizon.

Another limitation of this economic evaluation was the application of Canadian unit costs to resource use from the multina-

Table 5 Probabilistic base case results (40 years) - cost per QALY and LY (5,000 simulations)

\begin{tabular}{lllll}
\hline & Ticagrelor $(95 \% \mathrm{Cl})$ & Clopidogrel $(95 \% \mathrm{Cl})$ & Incremental $(95 \% \mathrm{Cl})$ & ICER $(95 \% \mathrm{Cl})$ \\
\hline Costs & $\$ 57,697(\$ 57,055-\$ 58,338)$ & $\$ 56,807(\$ 56,175-\$ 57,438)$ & $\$ 890(\$ 879-\$ 90 I)$ & - \\
LYs & $8.92(8.85-8.98)$ & $8.81(8.75-8.87)$ & $0.105(0.104-0.106)$ & $\$ 8,482(\$ 8,302-\$ 8,663)$ \\
QALYs & $7.43(7.38-7.48)$ & $7.34(\$ 56,175-\$ 57,438)$ & $0.090(0.089-0.090)$ & $\$ 9,942(\$ 9,764-\$ 10,120)$ \\
\hline
\end{tabular}

Note: All values are in Canadian dollars.

Abbreviations: Cl, confidence interval; ICER, incremental cost-effectiveness ratio; LY, life year; QALY, quality-adjusted life year. 


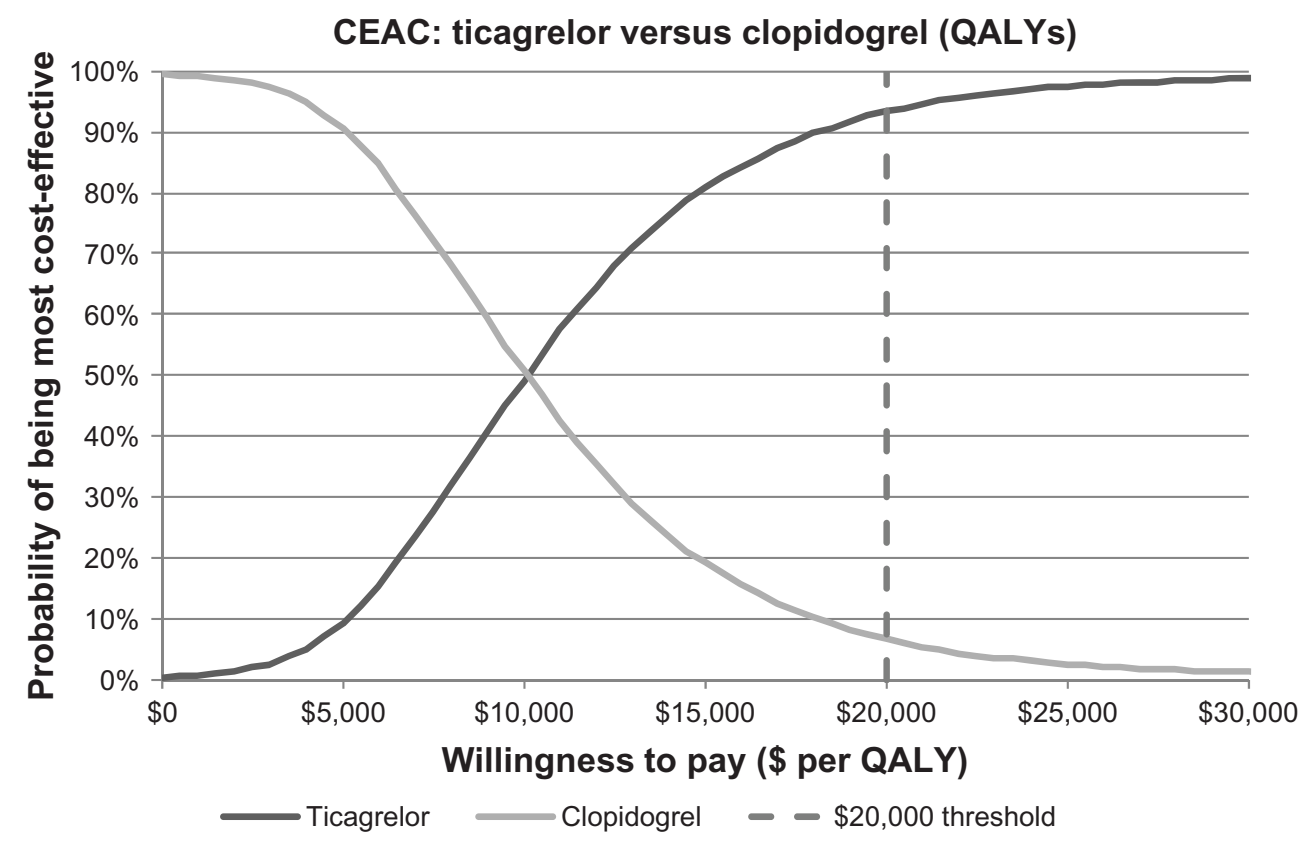

Figure 3 Cost-effectiveness acceptability curve for ticagrelor versus generic clopidogrel.

Note: All values are in Canadian dollars.

Abbreviations: CEAC, cost-effectiveness acceptability curve; QALY, quality-adjusted life year.

tional PLATO study. Canadian participation included 401 patients, or $2.2 \%$ of the overall trial population; it is possible that practice patterns in other countries differed from those in Canada. However, sensitivity analyses that used alternative published Canadian health state costs and utility data, ${ }^{18}$ instead of the PLATO-derived inputs, also support the cost-effectiveness of ticagrelor, with a ratio below \$15,000 per QALY gained. In the absence of long-term data, the model assumed conservatively no extension of treatment benefit beyond 1 year. The approach used to model subsequent events allowed multiple events (as utilized in a paper reported by Banerjee et al),${ }^{18}$ including a simplifying assumption such that the model did not allow patients in year 2 onwards to have a sub-

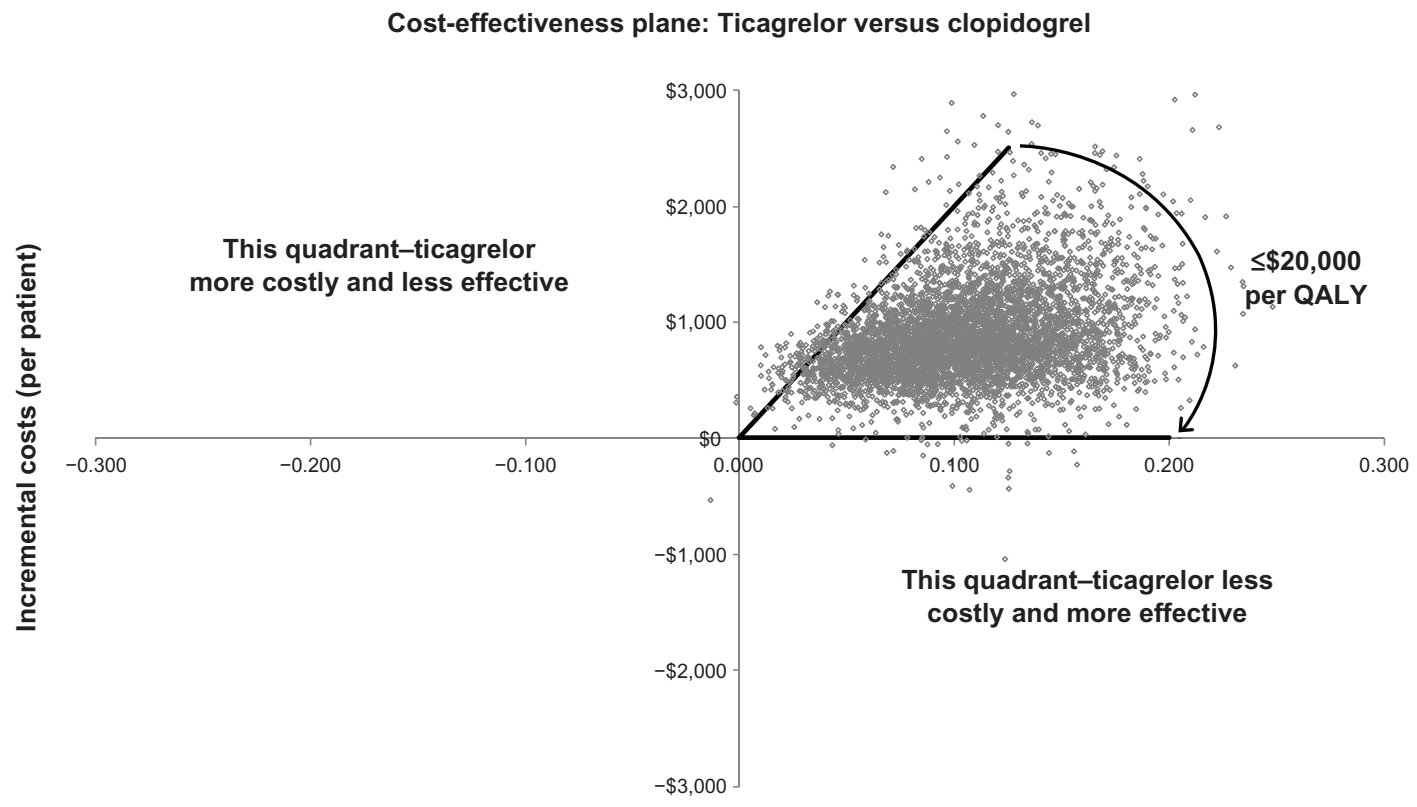

Incremental QALYs (per patient)

- Ticagrelor — $\$ 20,000$ threshold

Figure 4 Scatterplot of incremental costs and QALYs for ticagrelor compared to clopidogrel.

Note: All values are in Canadian dollars.

Abbreviations: QALY, quality-adjusted life year. 


\section{Tornado diagram: ticagrelor versus clopidogrel}

Hazard ratio for ticagrelor vs clopidogrel for death from any cause within tria Hazard ratio for ticagrelor vs clopidogrel for non-fatal MI within trial Hazard ratio for ticagrelor vs clopidogrel for non-fatal stroke within trial Probability of death from any cause within trial for clopidogrel Cost associated with no event state in Markov mode Utility associated with no event state in Markov model Probability of non-fatal MI within trial for clopidogrel Cost associated with post-MI state in Markov mode Cost associated with post-stroke state in Markov mode Cost associated with non-fatal Ml state in Markov mode Utility associated with post-stroke state in Markov mode Probability of non-fatal stroke within trial for clopidogre Cost associated with non-fatal stroke state in Markov mode Utility accrued in death any cause in decision tree Utility associated with post-MI state in Markov model

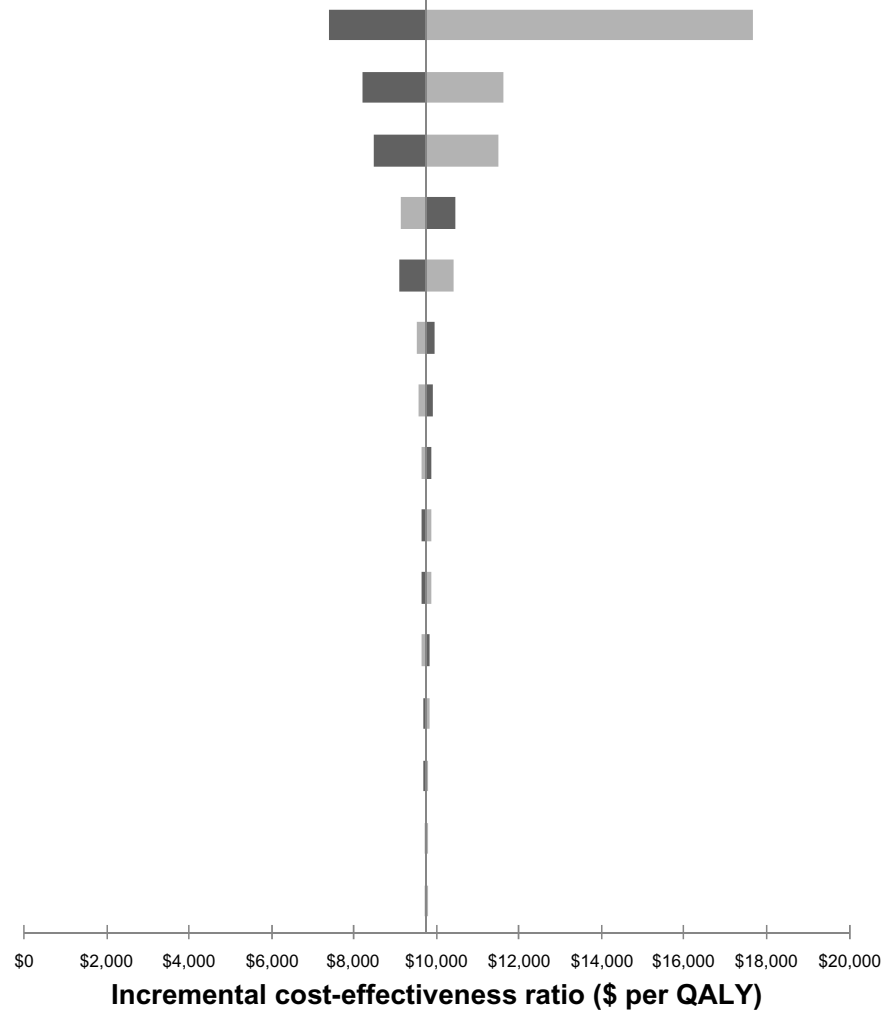

Figure $\mathbf{5}$ Tornado diagram of one-way sensitivity analyses for ticagrelor versus generic clopidogrel. The light shading represents the higher value for the input and dark shading represents the lower value for the input.

Note: All values are in Canadian dollars.

Abbreviations: MI, myocardial infarction; QALY, quality-adjusted life year; vs, versus.

sequent MI if they had previously had a stroke. This assumption was necessary to ensure that patients would not be considered to transition to a better health state than post-stroke, and is similar to that employed in a previously published model. ${ }^{18}$

To address some of these limitations, conservative assumptions regarding input parameters were used in the base case analyses wherever possible. These included using average health state utilities and costs from the PLATO trial to avoid a potential bias in favor of ticagrelor. For example, therapyspecific resource use and utility values reduced the cost-effectiveness ratio to below $\$ 5,000$ per QALY gained. In addition, the base case analysis and the majority of sensitivity analyses utilize the generic cost of clopidogrel, which is the lowest cost treatment option available. Use of the brand clopidogrel price resulted in a ratio of \$1,523 per QALY gained. Similarly, the mean number of days on study drug from the PLATO trial was not used; instead, 365 days of treatment was assumed in the base case analysis for patients who did not have a fatal event in year 1. Use of the PLATO trial data lowered the cost-effectiveness ratio to approximately $\$ 7,600$ per QALY gained.

Our findings are consistent with those from published PLATO-based ticagrelor cost-effectiveness studies. ${ }^{11,12}$ The current analyses differ from these previous studies by allowing multiple secondary cardiovascular events, adjusting the risk of events for the occurrence of prior events, adjusting the risk of events for age, and utilizing average health state costs and utilities rather than treatment-specific estimates.

\section{Conclusion}

The PLATO trial demonstrated significant reductions in the composite endpoint of cardiovascular death, MI, and stroke over a 1-year period with the use of ticagrelor versus clopidogrel in the treatment of ACS patients. ${ }^{8}$ The current analyses provides evidence that use of ticagrelor for 12 months in the management of ACS with or without ST elevation in the Canadian health care system is cost-effective compared with the use of brand or generic clopidogrel. The cost per QALY ratio of \$9,745 (0.084 QALY gained) versus generic clopidogrel is well below accepted thresholds for cost-effectiveness and consistent with other commonly used and reimbursed cardiovascular therapies in Canada. Overall, this study strongly supports the reimbursement and use of ticagrelor for the treatment of ACS patients in Canada. 


\section{Acknowledgments}

The authors wish to thank Jean-Eric Tarride for his review. SGG is supported by the Heart and Stroke Foundation of Ontario in his role as Heart and Stroke Foundation (Polo) Chair at the University of Toronto.

\section{Disclosure}

The study and development of the manuscript was supported by funding from AstraZeneca Canada. SGG has received research grant support from AstraZeneca, Bristol-Myers Squibb, Daiichi Sankyo, Eisai, Eli Lilly, Merck, Sanofi, and The Medicines Company; speaker/consulting honoraria from AstraZeneca, Bristol-Myers Squibb, Eli Lilly, Sanofi, Merck, and The Medicines Company; and salary support from the Heart and Stroke Foundation of Ontario/University of Toronto Cardiology Polo Chair. DTG is a shareholder and employee of Cornerstone Research Group Inc which received funding to conduct this study. STB is an employee of Cornerstone Research Group Inc. LK is an employee of AstraZeneca Canada. RG, PO, KRB, and KR have received honoraria from AstraZeneca.

\section{References}

1. Charles River Associates. The burden of acute coronary syndrome: The second leading cause of death in Canada. Charles River Associates' Life Sciences Practice. Available from: http://www.crai.ca/uploadedFiles/RELATING_MATERIALS/Publications/files/Burden $\% 20$ of $\% 20$ ACS\%20in\%20Canada_STC_151210Final\%20(2).pdf. Accessed November 4, 2011.

2. Bell AD, Roussin A, Cartier R, et al. The use of antiplatelet therapy in the outpatient setting: Canadian Cardiovascular Society guidelines. Can J Cardiol. 2011;27 Suppl A:S1-S59.

3. Yusuf S, Zhao F, Mehta SR, Chrolavicius S, Tognoni G, Fox KK. Effects of clopidogrel in addition to aspirin in patients with acute coronary syndromes without ST-segment elevation. N Engl J Med. 2001;345(7): 494-502.

4. Kuliczkowski W, Witkowski A, Polonski L, et al. Interindividual variability in the response to oral antiplatelet drugs: a position paper of the Working Group on antiplatelet drugs resistance appointed by the Section of Cardiovascular Interventions of the Polish Cardiac Society, endorsed by the Working Group on Thrombosis of the European Society of Cardiology. Eur Heart J. 2009;30(4):426-435.

5. Nguyen TA, Diodati JG, Pharand C. Resistance to clopidogrel: a review of the evidence. J Am Coll Cardiol. 2005;45(8):1157-1164.

6. Tanguay J-F, Bell AD, Ackman ML, et al. Focused 2012 Update on the Canadian Cardiovascular Society guidelines for the use of antiplatelet therapy. Can J Cardiol. August 23, 2013. [Epub ahead of print.]

7. Husted S, Emanuelsson H, Heptinstall S, Sandset PM, Wickens M, Peters G. Pharmacodynamics, pharmacokinetics, and safety of the oral reversible P2Y12 antagonist AZD6140 with aspirin in patients with atherosclerosis: a double-blind comparison to clopidogrel with aspirin. Eur Heart J. 2006;27(9):1038-1047.

8. Wallentin L, Becker RC, Budaj A, et al. Ticagrelor versus clopidogrel in patients with acute coronary syndromes. $N$ Engl J Med. 2009;361(11): 1045-1057.

9. Theidel U, Asseburg C, Giannitsis E, Katus H. Cost-effectiveness of ticagrelor versus clopidogrel for the prevention of atherothrombotic events in adult patients with acute coronary syndrome in Germany. Clin Res Cardiol. 2013;102(6):447-458.
10. Chin CT, Mellstrom C, Chua TS, Matchar DB. Lifetime cost-effectiveness analysis of ticagrelor in patients with acute coronary syndromes based on the PLATO trial: a Singapore healthcare perspective. Singapore Med J. 2013;54(3):169-175.

11. National Institute for Health and Clinical Excellence. Ticagrelor for the treatment of acute coronary syndromes (TA236). 2011. Available from: http://publications.nice.org.uk/ticagrelor-for-the-treatment-ofacute-coronary-syndromes-ta236. Accessed October 10, 2013.

12. Nikolic E, Janzon M, Hauch O, Wallentin L, Henriksson M. Costeffectiveness of treating acute coronary syndrome patients with ticagrelor for 12 months: results from the PLATO study. Eur Heart J. 2013;34(3):220-228.

13. Liew D, De Abreu Lourenco R, Adena M, Chim L, Aylward P. Costeffectiveness of 12-month treatment with ticagrelor compared with clopidogrel in the management of acute coronary syndromes. Clin Ther. 2013;35(8):1110-1117.

14. Canadian Agency for Drugs and Technologies in Health. CDEC Final Recommendation: Ticagrelor. 2011. Available from: http://www. cadth.ca/media/cdr/complete/cdr_complete_Brilinta_Dec-20-11.pdf. Accessed October 11, 2013.

15. Ontario Ministry of Health and Long-Term Care. Update at Ontario Drug Benefit Formulary/Comparative Drug Index No 41. Effective April 30, 2013. Available from: http://www.health.gov.on.ca/en/pro/ programs/drugs/formulary/41_update_at_20130419.pdf. Accessed October 11, 2013.

16. Canadian Agency for Drugs and Technologies in Health. Guidelines for the economic evaluation of health technologies. Canada. 3rd ed. 2006. Available from: http://www.cadth.ca/media/pdf/186_ EconomicGuidelines_e.pdf. Accessed October 11, 2013.

17. Briggs A, Claxton K, Sculpher M. Decision Modelling For Health Economic Evaluation. Oxford, UK: Oxford University Press; 2006.

18. Canadian Agency for Drugs and Technologies in Health. Adapted from: Banerjee S, Brown A, McGahan L, et al. Clopidogrel versus other antiplatelet agents for secondary prevention of vascular events in adults with acute coronary syndrome or peripheral vascular disease: clinical and cost-effectiveness analyses. [Technology Report, No 133]. Ottawa, Canada: Canadian Agency for Drugs and Technologies in Health; 2010. Available from: http:/www.cadth.ca/media/pdf/cadth2-1-02.pdf. Accessed October 11, 2013.

19. Karnon J, Brennan A, Pandor A, et al. Modelling the long term cost effectiveness of clopidogrel for the secondary prevention of occlusive vascular events in the UK. Curr Med Res Opin. 2005;21(1):101-112.

20. Statistics Canada. Life Tables, Canada, Provinces and Territories. 2011. Available from: http://www5.statcan.gc.ca/bsolc/olc-cel/olccel?catno=84-537-X\&lang=eng. Accessed October 11, 2013.

21. Lacey EA, Walters SJ. Continuing inequality: gender and social class influences on self perceived health after a heart attack. J Epidemiol Community Health. 2003;57(8):622-627.

22. Storey RF, Becker RC, Harrington RA, et al. Characterization of dyspnoea in PLATO study patients treated with ticagrelor or clopidogrel and its association with clinical outcomes. Eur Heart J. 2011;32(23): 2945-2953.

23. Ontario Case Costing Initiative. 2010. Available from: http://www.occp. com/. Accessed October 11, 2013.

24. Ontario Ministry of Health and Long-Term Care. Ontario Health Insurance (OHIP) Schedule of Benefits and Fees (Physicians). 2010. Available from: http:/www.health.gov.on.ca/english/providers/program/ohip/sob/ physserv/physserv_mn.html. Accessed October 11, 2013.

25. Crespin DJ, Federspiel JJ, Biddle AK, Jonas DE, Rossi JS. Ticagrelor versus genotype-driven antiplatelet therapy for secondary prevention after acute coronary syndrome: a cost-effectiveness analysis. Value Health. 2011;14(4):483-491.

26. Laupacis A, Feeny D, Detsky AS, Tugwell PX. How attractive does a new technology have to be to warrant adoption and utilization? Tentative guidelines for using clinical and economic evaluations. CMAJ. 1992;146(4):473-481. 


\section{Supplementary material Costing methodology}

The Ontario Case Costing Initiative (OCCI) provides average costs for hospitalizations and average number of hospital days for various hospitalizations such that an average cost per day can be calculated (eg, average cost per day for the treatment of myocardial infarction [MI] patients). Based on 2,089 hospitalizations associated with unstable angina and MI (I200, I201, I2080, I2088, I209, and I219) in the current OCCI database (average of $\$ 7,086$ per hospitalization in 2008 Canadian dollars for an average of 45 days), an average cost per day of $\$ 1,612$ (inflated to 2011) was used to cost the number of days spent in cardiac or coronary care units or in the general ward. ${ }^{1}$ The PLATO (Platelet Inhibition and Patient Outcomes) trial also collected the number of days spent in the Intensive Care Unit (ICU) which were valued at $\$ 3,932 /$ day based on OCCI data.

In the absence of patient-level data, this method of using an average cost per day combined with the average length of stay in hospital for trial patients for various events allows for a more accurate costing of hospitalizations as observed in the clinical trial as opposed to using the average length of stay for patients in the OCCI database. However, OCCI does not capture physician fees billed separately to the Ontario government for minor and major procedures and investigations, and as such these were separately included in the costing analysis. To avoid double counting of the hospital stay, only the additional costs beyond hospital stay were estimated (eg, physician fees) and applied for each procedure and intervention recorded in the PLATO trial.

For each event (no event, MI, stroke, or death), the average cost across the two arms of the study was used in the model (Table S1). This average cost per health event was used instead of treatment-specific costing to avoid artificial differences in health event costs between treatment arms that may be caused by normal heterogeneity in resource use between patients. Further, the Swedish trial-based economic evaluation of the PLATO trial did not show a statistical difference in costs between the treatment groups. ${ }^{2}$ The authors mentioned that the PLATO subeconomic study may not have been powered to detect cost differences between treatment arms. As such, random variability in resource use could artificially inflate resource use in one treatment arm. For example, the costs of stroke and death in the clopidogrel arm were substantially higher than in the ticagrelor arm.
For these reasons, an average cost per health state was used in the 1-year decision tree. A sensitivity analysis was conducted with treatment-specific health state costs.

The costs of the 'no event' state and the other health states include the resource use for the management of the initial ACS: as such, the cost in all these states may be higher than typical costs for a patient with stable cardiovascular disease or an MI patient who did not have ACS in the preceding 12-month period.

\section{Subgroup analysis}

In addition to the economic evaluation based on the full PLATO population, a number of subgroup analyses were undertaken, the results of which are shown in Table S6. The subgroups included in the analysis were: 12-month cohort, ST segment elevation myocardial infarction, non-ST segment elevation myocardial infarction, unstable angina, diabetes, no diabetes, patients on low dose acetylsalicylic acid, invasive and medically managed. In all cases, the ratio remained below $\$ 11,500$ per QALY, further demonstrating the costeffectiveness of ticagrelor (Table S6).

\section{References}

1. Ontario Case Costing Initiative (OCCI). 2010. Available from: http:// www.occp.com/. Accessed October 11, 2013.

2. Nikolic E, Janzon M, Hauch O, Wallentin L, Henriksson M. Costeffectiveness of treating acute coronary syndrome patients with ticagrelor for 12 months: results from the PLATO study. Eur Heart J. 2013;34(3):220-228.

3. Ontario Drug Benefits Program. Drugs Funded by Ontario Drug Benefit (ODB) Program. 2011. Available from: https://www.healthinfo.moh.gov. on.ca/formulary/index.jsp. Accessed October 11, 2013.

4. Ontario Ministry of Health and Long-Term Care. Chronic Ventilation Strategy Task Force. 2006. Available from: http://www.stmichaelshospital. com/pdf/crich/sru-cvs-task-force.pdf. Accessed October 11, 2013.

5. Ontario Ministry of Health and Long-Term Care. Ontario Health Insurance (OHIP) Schedule of Benefits and Fees (Physicians). 2010. Available from: http://www.health.gov.on.ca/english/providers/program/ohip/sob/ physserv/physserv_mn.html. Accessed October 11, 2013.

6. Goeree R, Bowen JM, Blackhouse G, et al. Economic evaluation of drug-eluting stents compared to bare metal stents using a large prospective study in Ontario. Int $J$ Technol Assess Health Care. 2009;25(2):196-207.

7. Callum JL, Pinkerton PH; Sunnybrook and Women's College Health Sciences Centre. Bloody Easy 2: Blood Transfusions, Blood Alternatives and Transfusion Reactions: A Guide to Transfusion Medicine. 2nd ed. Toronto, Canada: Sunnybrook and Women's College Health Sciences Centre; 2005.

8. Karnon J, Brennan A, Pandor A, et al. Modelling the long term cost effectiveness of clopidogrel for the secondary prevention of occlusive vascular events in the UK. Curr Med Res Opin. 2005;21(1):101-112.

9. Crespin DJ, Federspiel JJ, Biddle AK, Jonas DE, Rossi JS. Ticagrelor versus genotype-driven antiplatelet therapy for secondary prevention after acute coronary syndrome: a cost-effectiveness analysis. Value Health. 2011;14(4):483-491. 
Table SI Health state costs used in the first year of the model (20I I costs)

\begin{tabular}{llll}
\hline State & Clopidogrel & Ticagrelor & Average for both treatment groups \\
\hline No further event & $\$ 21,735$ & $\$ 21,828$ & $\$ 21,781$ \\
New Ml (nonfatal) & $\$ 45,205$ & $\$ 45,824$ & $\$ 45,515$ \\
New stroke (nonfatal) & $\$ 59,133$ & $\$ 51,758$ & $\$ 55,445$ \\
Dead any cause & $\$ 44,663$ & $\$ 34,597$ & $\$ 39,630$ \\
\hline
\end{tabular}

Notes: Values rounded for display, inflated to 201 I costs. All values are in Canadian dollars.

Abbreviation: $\mathrm{Ml}$, myocardial infarction.

Table S2 Unit costs (20I I Canadian\$)

\begin{tabular}{|c|c|c|c|}
\hline Cost item & Unit & 2011 Cost $^{*}$ & Source \\
\hline \multicolumn{4}{|l|}{ Drugs } \\
\hline Daily ticagrelor & 90 mg twice daily & $\$ 2.96$ & AstraZeneca Canada \\
\hline Loading dose ticagrelor & $180 \mathrm{mg}$ & $\$ 2.96$ & AstraZeneca Canada \\
\hline Loading dose clopidogrel & $300 \mathrm{mg}$ & $\$ 10.31$ (generic $\$ 2.58$ ) & Ontario Drug Benefit Program ${ }^{3}$ \\
\hline Daily clopidogrel & 75 mg once daily & $\$ 2.58$ & Ontario Drug Benefit Program ${ }^{3}$ \\
\hline Daily clopidogrel (generic) & 75 mg once daily & $\$ 0.645$ & Calculated ( $25 \%$ of brand name) \\
\hline Daily ASA & $75-150 \mathrm{mg}$ & $\$ 0$ & Equivalent between two groups \\
\hline \multicolumn{4}{|l|}{ Hospitalizations } \\
\hline General ward, cardiac care unit, & Per day & $\$ 1,612$ & Ontario Case Costing Initiative ${ }^{\prime}$ \\
\hline and coronary care ward & & & $\begin{array}{l}\text { Based on average cost per day for CCU for UA } \\
\text { and } M I(1200,1201,12080,12088,1209 \text {, and I219) }\end{array}$ \\
\hline Intensive care unit & Per day & $\$ 3,932$ & Ministry of Health and Long-Term Care ${ }^{4}$ \\
\hline \multicolumn{4}{|l|}{ Interventions (physician fees) } \\
\hline CABG with valve replacement & Per operation & $\$ 7,396$ & Ontario Schedule of Benefits ${ }^{5}$ \\
\hline CABG without valve replacement & Per operation & $\$ 6,001$ & Ontario Schedule of Benefits ${ }^{5}$ \\
\hline Implantable cardiac defibrillator & Per procedure & $\$ 1,096$ & Ontario Schedule of Benefits ${ }^{5}$ \\
\hline Intra-aortic balloon pump & Per procedure & $\$ 312$ & Ontario Schedule of Benefits ${ }^{5}$ \\
\hline Left ventricular assist device & Per procedure & $\$ 2,817$ & Ontario Schedule of Benefits ${ }^{5}$ \\
\hline \multicolumn{4}{|l|}{ Pacemaker } \\
\hline Implantation of single chamber & Per procedure & $\$ 487$ & Ontario Schedule of Benefits ${ }^{5}$ \\
\hline rate-responsive pacemaker & & & \\
\hline $\mathrm{PCl}$ without stent & Per procedure & $\$ 567$ & Ontario Schedule of Benefits ${ }^{5}$ \\
\hline $\mathrm{PCl}$ with stent & Per procedure & $\$ 647$ & Ontario Schedule of Benefits ${ }^{5}$ \\
\hline Bare metal stent & Per unit & $\$ 600$ & Goeree et $\mathrm{al}^{6}$ \\
\hline Drug-eluting stent & Per unit & $\$ 1,899$ & Goeree et $\mathrm{al}^{6}$ \\
\hline \multicolumn{4}{|l|}{ Investigations (physician fees) } \\
\hline Coronary angiography & Per procedure & $\$ 212$ & Ontario Schedule of Benefits ${ }^{5}$ \\
\hline $\mathrm{CT}$ abdomen & Per procedure & $\$ 115$ & Ontario Schedule of Benefits ${ }^{5}$ \\
\hline CT chest & Per procedure & $\$ 92$ & Ontario Schedule of Benefits ${ }^{5}$ \\
\hline \multicolumn{4}{|l|}{ CT extremity } \\
\hline $\mathrm{CT}$, arm & Per procedure & Assumed all were leg & Ontario Schedule of Benefits ${ }^{5}$ \\
\hline CT, leg & Per procedure & $\$ 81$ & Ontario Schedule of Benefits ${ }^{5}$ \\
\hline \multicolumn{4}{|l|}{$C T$ head/brain } \\
\hline CT, head & Per procedure & $\$ 81$ & Ontario Schedule of Benefits ${ }^{5}$ \\
\hline $\mathrm{CT}$, brain & Per procedure & Assumed all were head & Ontario Schedule of Benefits ${ }^{5}$ \\
\hline CT helical & Per procedure & Assumed the same as spine & Ontario Schedule of Benefits ${ }^{5}$ \\
\hline CT spine & Per procedure & $\$ 115$ & Ontario Schedule of Benefits ${ }^{5}$ \\
\hline Echocardiography & Per procedure & $\$ 140$ & Ontario Schedule of Benefits ${ }^{5}$ \\
\hline Electrophysiology study & Per procedure & $\$ 1,608$ & Ontario Schedule of Benefits ${ }^{5}$ \\
\hline Holter study & Per procedure & $\$ 273$ & Ontario Schedule of Benefits ${ }^{5}$ \\
\hline MRI abdomen & Per procedure & $\$ 78$ & Ontario Schedule of Benefits ${ }^{5}$ \\
\hline MRI chest & Per procedure & $\$ 78$ & Ontario Schedule of Benefits ${ }^{5}$ \\
\hline MRI extremity & Per procedure & $\$ 67$ & Ontario Schedule of Benefits ${ }^{5}$ \\
\hline \multirow[t]{2}{*}{ MRI, arm } & Per procedure & Assumed same as & Ontario Schedule of Benefits ${ }^{5}$ \\
\hline & & CT extremity & \\
\hline \multirow[t]{2}{*}{ MRI, leg } & Per procedure & Assumed same as & Ontario Schedule of Benefits ${ }^{5}$ \\
\hline & & CT extremity & \\
\hline
\end{tabular}


Table S2 (Continued)

\begin{tabular}{|c|c|c|c|}
\hline Cost item & Unit & $20 I I$ Cost $^{*}$ & Source \\
\hline MRI head/brain & Per procedure & $\$ 74$ & Ontario Schedule of Benefits ${ }^{5}$ \\
\hline \multirow[t]{2}{*}{ MRI, head } & Per procedure & Assumed same as & Ontario Schedule of Benefits ${ }^{5}$ \\
\hline & & CT head/brain & \\
\hline \multirow[t]{2}{*}{ MRI, brain } & Per procedure & Assumed same as & Ontario Schedule of Benefits ${ }^{5}$ \\
\hline & & CT head/brain & \\
\hline MRI spine & Per procedure & $\$ 108$ & Ontario Schedule of Benefits ${ }^{5}$ \\
\hline Myocardial scintigraphy & Per procedure & $\$ 166$ & Ontario Schedule of Benefits ${ }^{5}$ \\
\hline Pulmonary angiography & Per procedure & $\$ 120$ & Ontario Schedule of Benefits ${ }^{5}$ \\
\hline Stress test & Per procedure & $\$ 98$ & Ontario Schedule of Benefits ${ }^{5}$ \\
\hline Ventilation/perfusion scan & Per procedure & $\$ 301$ & Ontario Schedule of Benefits ${ }^{5}$ \\
\hline \multicolumn{4}{|l|}{ Bleeds } \\
\hline Reoperation due to bleeding & Per operation & $\$ 694$ & Ontario Schedule of Benefits ${ }^{5}$ \\
\hline Unit of fresh frozen plasma & Per unit & $\$ 249$ & Callum and Pinkerton ${ }^{7}$ \\
\hline Unit of packed red blood cells & Per unit & $\$ 453$ & Callum and Pinkerton ${ }^{7}$ \\
\hline Unit of platelets & Per unit & $\$ 566$ & Callum and Pinkerton ${ }^{7}$ \\
\hline Unit of whole blood & Per unit & $\$ 453$ & Callum and Pinkerton ${ }^{7}$ \\
\hline \multicolumn{4}{|l|}{ Significant adverse events } \\
\hline Dyspnea & Physician visits & $\$ 35.40 * 2=\$ 70.80$ & Ontario Schedule of Benefits ${ }^{5}$ \\
\hline
\end{tabular}

Notes: *In some instances costs were inflated to 20II. All values are in Canadian dollars.

Abbreviations: ASA, acetylsalicylic acid; CABG, coronary artery bypass surgery; CCU, coronary care unit; CT, computed tomography; MI, myocardial infarction; MRI, magnetic resonance imaging; $\mathrm{PCl}$, percutaneous coronary intervention; $\mathrm{UA}$, unstable angina.

Table S3 Values used in one-way sensitivity analysis

\begin{tabular}{|c|c|c|c|c|}
\hline \multirow[t]{2}{*}{ Variable } & \multirow[t]{2}{*}{ Parameter } & \multicolumn{2}{|l|}{ Range } & \multirow[t]{2}{*}{ Source } \\
\hline & & Low & High & \\
\hline \multicolumn{5}{|c|}{ Event rates for clopidogrel (I-year decision tree) } \\
\hline Dead any cause & 0.0545 & 0.0500 & 0.0590 & \multirow{3}{*}{$\begin{array}{l}95 \% \text { confidence intervals } \\
\text { based on PLATO data }\end{array}$} \\
\hline Nonfatal MI & 0.0522 & 0.0477 & 0.0567 & \\
\hline Nonfatal stroke & 0.0080 & 0.0062 & 0.0097 & \\
\hline \multicolumn{5}{|c|}{ Hazard ratios for ticagrelor versus clopidogrel (I-year decision tree) } \\
\hline Dead any cause & 0.78 & 0.69 & 0.89 & \multirow{3}{*}{$\begin{array}{l}95 \% \text { confidence intervals } \\
\text { based on PLATO data }\end{array}$} \\
\hline Nonfatal MI & 0.86 & 0.76 & 0.98 & \\
\hline Nonfatal stroke & 1.09 & 0.80 & 1.49 & \\
\hline \multicolumn{5}{|l|}{ Utilities from PLATO study } \\
\hline No further event & 0.875 & 0.871 & 0.879 & \multirow{8}{*}{$\begin{array}{l}95 \% \text { confidence intervals } \\
\text { based on PLATO HECON } \\
\text { substudy }\end{array}$} \\
\hline New MI & 0.812 & 0.792 & 0.832 & \\
\hline New stroke & 0.736 & 0.662 & 0.810 & \\
\hline Dead any cause & 0.249 & 0.222 & 0.276 & \\
\hline New MI (mm) & 0.812 & 0.792 & 0.832 & \\
\hline Post-Ml/no event (mm) & 0.854 & 0.834 & 0.873 & \\
\hline New stroke $(\mathrm{mm})$ & 0.736 & 0.662 & 0.810 & \\
\hline Post-stroke (mm) & 0.736 & 0.662 & 0.810 & \\
\hline \multicolumn{5}{|c|}{ Resource cost for the Markov model } \\
\hline New MI & $\$ 10,824$ & $\$ 8,659$ & $\$ 12,989$ & \multirow[t]{4}{*}{ Costs were varied by $\pm 20 \%$} \\
\hline Post-MI/no event & $\$ 3,112$ & $\$ 2,490$ & $\$ 3,734$ & \\
\hline New stroke & $\$ 20,823$ & $\$ 16,658$ & $\$ 24,988$ & \\
\hline Post-stroke & $\$ 4,336$ & $\$ 3,469$ & $\$ 5,203$ & \\
\hline
\end{tabular}

Note: All values are in Canadian dollars.

Abbreviations: MI, myocardial infarction; PLATO, Platelet Inhibition and Patient Outcomes. 
Table S4 Summary of probabilistic sensitivity analysis inputs and distributions

\begin{tabular}{|c|c|c|c|}
\hline Variable & Value $(95 \% \mathrm{Cl})$ & Distribution & Source \\
\hline \multicolumn{4}{|c|}{ Event rates for clopidogrel (I-year decision tree) } \\
\hline Dead any cause & $0.0545(0.05-0.059)$ & Lognormal & \multirow[t]{3}{*}{ Based on the raw data from the PLATO study } \\
\hline Nonfatal MI & $0.0522(0.0477-0.0567)$ & Lognormal & \\
\hline Nonfatal stroke & $0.008(0.0062-0.0097)$ & Lognormal & \\
\hline \multicolumn{4}{|c|}{ Hazard ratios for ticagrelor versus clopidogrel (I-year decision tree) } \\
\hline Dead any cause & $0.78(0.69-0.89)$ & Lognormal & \multirow[t]{3}{*}{ Based on the PLATO study } \\
\hline Nonfatal MI & $0.86(0.76-0.98)$ & Lognormal & \\
\hline Nonfatal stroke & $1.09(0.80-1.49)$ & Lognormal & \\
\hline \multicolumn{4}{|l|}{ Event rates (Markov model) } \\
\hline $\begin{array}{l}\text { Subsequent events (Ml, stroke, } \\
\text { and vascular death) }\end{array}$ & Various & Normal & $\begin{array}{l}\text { Coefficients for the risk equations from Karnon } \\
\text { et al }{ }^{8} \text { were varied around their respective SE }\end{array}$ \\
\hline \multicolumn{4}{|c|}{ Utility values (decision tree and Markov model) } \\
\hline No further event & $0.875(0.87 I-0.879)$ & Beta & \multirow{4}{*}{$\begin{array}{l}95 \% \mathrm{cc} \\
\text { study }\end{array}$} \\
\hline New MI & $0.8120(0.792-0.832)$ & Beta & \\
\hline New stroke & $0.7360(0.662-0.810)$ & Beta & \\
\hline Dead any cause & $0.2490(0.222-0.726)$ & Beta & \\
\hline \multicolumn{4}{|l|}{ Resource costs (decision tree) } \\
\hline No further event (ticagrelor) & $\$ 21,911$ & Gamma & \multirow{8}{*}{$\begin{array}{l}\text { Based on } 95 \% \text { confidence intervals of } \\
\text { resource use from the PLATO study }\end{array}$} \\
\hline New MI (ticagrelor) & $\$ 46,024$ & Gamma & \\
\hline New stroke (ticagrelor) & $\$ 51,351$ & Gamma & \\
\hline Dead any cause (ticagrelor) & $\$ 34,387$ & Gamma & \\
\hline No further event (clopidogrel) & $\$ 21,849$ & Gamma & \\
\hline New MI (clopidogrel) & $\$ 45,298$ & Gamma & \\
\hline New stroke (clopidogrel) & $\$ 58,769$ & Gamma & \\
\hline Dead any cause (clopidogrel) & $\$ 44,391$ & Gamma & \\
\hline \multicolumn{4}{|l|}{ Resource costs (Markov model) } \\
\hline New MI & $\$ 10,824$ & Gamma & \multirow{4}{*}{$\begin{array}{l}\text { As no standard error was reported in the } \\
\text { original study, we assumed an SE equal to the } \\
\text { mean }\end{array}$} \\
\hline Post-MI/no event & $\$ 3,112$ & Gamma & \\
\hline New stroke & $\$ 20,823$ & Gamma & \\
\hline Post-stroke & $\$ 4,336$ & Gamma & \\
\hline
\end{tabular}

Note: All values are in Canadian dollars.

Abbreviations: $\mathrm{Cl}$, confidence interval; $\mathrm{MI}$, myocardial infarction; SE, standard error; PLATO, Platelet Inhibition and Patient Outcomes.

Table S5 Output of one-way sensitivity analyses: incremental cost per QALY for ticagrelor versus clopidogrel

\begin{tabular}{|c|c|c|}
\hline Parameters & Low value & High value \\
\hline Hazard ratio for ticagrelor versus clopidogrel for death from any cause within trial & $\$ 7,391$ & $\$ 17,685$ \\
\hline Hazard ratio for ticagrelor versus clopidogrel for nonfatal MI within trial & $\$ 8,209$ & $\$ 11,618$ \\
\hline Hazard ratio for ticagrelor versus clopidogrel for nonfatal stroke within trial & $\$ 8,465$ & $\$ 11,479$ \\
\hline Probability of death from any cause within trial for clopidogrel & $\$ 10,467$ & $\$ 9,120$ \\
\hline Probability of nonfatal MI within trial for clopidogrel & $\$ 9,927$ & $\$ 9,564$ \\
\hline Probability of nonfatal stroke within trial for clopidogrel & $\$ 9,657$ & $\$ 9,830$ \\
\hline Probability of dyspnea whilst on ticagrelor & $\$ 9,739$ & $\$ 9,750$ \\
\hline Probability of dyspnea whilst on clopidogrel & $\$ 9,749$ & $\$ 9,740$ \\
\hline Cost associated with no event state in Markov model & $\$ 9,090$ & $\$ 10,398$ \\
\hline Cost associated with post-MI state in Markov model & $\$ 9,865$ & $\$ 9,624$ \\
\hline Cost associated with post-stroke state in Markov model & $\$ 9,628$ & $\$ 9,861$ \\
\hline Cost associated with nonfatal MI state in Markov model & $\$ 9,632$ & $\$ 9,857$ \\
\hline Cost associated with nonfatal stroke state in Markov model & $\$ 9,688$ & $\$ 9,801$ \\
\hline Cost of dyspnea in primary care & $\$ 9,719$ & $\$ 9,770$ \\
\hline Cost of brand clopidogrel & - & $\$ 1,523$ \\
\hline Cost of generic clopidogrel ( $20 \%$ brand price) & - & $\$ 10,293$ \\
\hline Utility accrued in no event in decision tree & $\$ 9,753$ & $\$ 9,736$ \\
\hline Utility accrued in death any cause in decision tree & $\$ 9,708$ & $\$ 9,782$ \\
\hline Utility accrued in nonfatal $\mathrm{MI}$ in decision tree & $\$ 9,728$ & $\$ 9,761$ \\
\hline Utility accrued in nonfatal stroke in decision tree & $\$ 9,751$ & $\$ 9,738$ \\
\hline Utility associated with no event state in Markov model & $\$ 9,962$ & $\$ 9,536$ \\
\hline Utility associated with nonfatal MI state in Markov model & $\$ 9,746$ & $\$ 9,743$ \\
\hline Utility associated with nonfatal stroke state in Markov model & $\$ 9,757$ & $\$ 9,732$ \\
\hline Utility associated with post-MI state in Markov model & $\$ 9,709$ & $\$ 9,780$ \\
\hline Utility associated with post-stroke state in Markov model & $\$ 9,839$ & $\$ 9,651$ \\
\hline Utility associated with dyspnea (utility reduced by $7 \%$ for 7 days ${ }^{9}$ ) & - & $\$ 9,849$ \\
\hline
\end{tabular}

Note: All values are in Canadian dollars.

Abbreviations: MI, myocardial infarction; QALY, quality-adjusted life year. 
Table S6 Summary of subgroup analysis (40-year time horizon)

\begin{tabular}{ll}
\hline Subgroup & Incremental cost per QALY gained \\
\hline I2-month cohort & $\$ 10,020$ \\
STEMI & $\$ 10,596$ \\
NSTEMI & $\$ 7,959$ \\
Unstable angina & $\$ 11,499$ \\
Diabetes & $\$ 7,950$ \\
No diabetes & $\$ 10,285$ \\
Low dose ASA & $\$ 6,573$ \\
Invasive & $\$ 11,043$ \\
Medically managed & $\$ 7,042$ \\
\hline
\end{tabular}

Note: All values are in Canadian dollars.

Abbreviations: ASA, acetylsalicylic acid; NSTEMI, non-ST segment myocardial infarction; QALY, quality-adjusted life year; STEMI, ST segment elevation myocardial infarction.

\section{Publish your work in this journal}

ClinicoEconomics \& Outcomes Research is an international, peerreviewed open-access journal focusing on Health Technology Assessment, Pharmacoeconomics and Outcomes Research in the areas of diagnosis, medical devices, and clinical, surgical and pharmacological intervention. The economic impact of health policy and health systems organization also constitute important areas of coverage. The manuscript management system is completely online and includes a very quick and fair peer-review system, which is all easy to use. Visit http://www.dovepress.com/testimonials.php to read real quotes from published authors.

Submit your manuscript here: http://www.dovepress.com/clinicoeconomics-and-outcomes-research-journal 